\title{
Exercise-Induced Bronchoconstriction Diagnostics: Impact of a Repeated Exercise Challenge Test
}

\author{
Maj R. Angell1', Liv Berit Augestad1, Thorbjørn S. Haugen², Anne Frostad², \\ Thor Arne Grønnerød ${ }^{2}$, Trine Stensrud ${ }^{3 *}$ \\ ${ }^{1}$ Department of Human Movement Science, Faculty of Social Sciences and Technology Management, \\ Norwegian University of Science and Technology (NTNU), Trondheim, Norway \\ ${ }^{2}$ Clinic for Allergy and Airway Diseases, Oslo, Norway \\ ${ }^{3}$ Department of Sports Medicine, Norwegian School of Sport Sciences, Oslo, Norway \\ Email: trine.stensrud@nih.no
}

Received 3 February 2014; revised 3 March 2014; accepted 10 March 2014

Copyright (C) 2014 by authors and Scientific Research Publishing Inc.

This work is licensed under the Creative Commons Attribution International License (CC BY).

http://creativecommons.org/licenses/by/4.0/

(c) (i) Open Access

\section{Abstract}

Exercise-Induced bronchoconstriction (EIB) is related to increased ventilation (VE) during exercise and describes the transient airway narrowing following exercise. A reliable diagnosis is essential for optimal treatment. The impact of a repeated exercise challenge test (ECT) in a clinical setting is not well established and conducting a repeated ECT with the possibility to adjust the exercise intensity on an individual basis may give more information. The aim of the study was to evaluate the test-retest reliability of an ECT for EIB and its association with exercise intensity. Methods: After examination by a pulmonologist, 20 referred subjects with symptoms strong indications of Exercise-Induced bronchoconstriction performed two consecutive exercise challenge tests on a treadmill. The exercise intensity of the repeated test was adjusted. Forced expiratory volume in 1 second $\left(F V_{1}\right)$ was measured before and 1, 3, 6, 10, and 15 minutes after exercise. EIB was defined as a reduction of $\geq 10 \%$ in $\mathrm{FEV}_{1}$. Ventilation and heart rate were measured during exercise. Results: Five subjects tested positive in both tests, and ten subjects tested negative in both tests. Three subjects tested positive in the first test only, while two subjects tested positive in the second test only. The exercise intensity was not significantly different between the two tests for any of the subjects. Conclusion: There were $25 \%$ divergences in the diagnostic results of two consecutive exercise challenge tests. The difference in the test results was not explained by a difference in the exercise intensity.

\section{Keywords}

Exercise-Induced Bronchoconstriction, Exercise Challenge Test, Forced Expiratory Volume in 1

\footnotetext{
${ }^{*}$ Corresponding author.
} 


\section{Second, Exercise Intensity}

\section{Introduction}

Exercise-Induced bronchoconstriction (EIB) is related to increased ventilation (VE) during exercise and describes the transient airway narrowing following exercise [1]. The symptoms of EIB include coughing, wheezing, shortness of breath, premature fatigue, and chest tightness [1] [2]. As EIB may be the first sign of asthma [3], a reliable diagnosis is essential for optimal treatment.

The prevalence of EIB in the general population worldwide is poorly defined [4], and the reported prevalence in the literature varies due to discrepancy in methods used for diagnosis, e.g. self-reported symptoms as opposed to objective lung-function measurements [5]. Rupp [4] reports a 12\% - 15\% prevalence of EIB in the general population. EIB is reported in most asthmatic patients and is also more frequent in atopic individuals [4].

Symptoms alone are not very sensitive or specific predictors of EIB [5]. In order to diagnose the presence of EIB, reported symptoms can be confirmed by using different provocation tests. A standardized exercise challenge test (ECT) on a treadmill can be performed, whereby the pulmonary function is measured by spirometry. The response to exercise is assessed as the post-exercise reduction in forced expiratory volume in 1 second $\left(\mathrm{FEV}_{1}\right)$ expressed as a percentage of the pre-exercise value. Both the European Respiratory Society (ERS) and the American Thoracic Society (ATS) recommendations set a $\geq 10 \%$ reduction in $\mathrm{FEV}_{1}$ as a criterion for EIB [6] [7].

Exercise intensity influences the sensitivity of an ECT because the major factor determining the severity of EIB is the level of pulmonary VE reached and sustained during exercise. An ECT can be acceptably sensitive and specific if exercise minute ventilation is standardized [8]. Accordingly, ATS guidelines state that VE during an ECT should reach $40 \%-60 \%$ of the predicted maximum voluntary ventilation (MVV), measured or estimated as $\mathrm{FEV}_{1} \times 35$, for a period of 4 minutes, with total test duration of $6-8$ minutes. Correspondingly, the guidelines recommend an exercise intensity of $80 \%-90 \%$ of maximum heart rate $\left(\mathrm{HR}_{\max }\right)$, estimated by the formula $\mathrm{HR}_{\max }=220$ - age, the last 4 minutes of the test [6]. However, as there is high individual variance in $\mathrm{HR}_{\max }$ [9], it has been reported that heart rate based on ATS standard protocols may not ensure sufficient exercise intensity to induce bronchoconstriction [10]. Moreover, a study by Carlsen et al. [11] has demonstrated a significantly increased reduction in lung function after an ECT performed at $95 \%$ of estimated $\mathrm{HR}_{\max }$ compared to an intensity of $85 \%$ of estimated $\mathrm{HR}_{\max }$. Thus, adequate intensity of an ECT may be essential to achieve a reliable diagnosis of EIB.

The impact of a repeated ECT in a clinical setting is not well established. However, the reproducibility of an ECT has been investigated. A study by Anderson et al. [12] found an agreement of $76 \%$ between two ECTs when examining subjects without a definite diagnosis of asthma. The results demonstrated variability in the presence and severity of EIB, despite standardization of intensity, duration, and condition of the inspired air, and suggest that more than one ECT may be required to exclude or to diagnose EIB.

The HR formula recommended by the ATS, as described above, is usually applied [13]. Trümper et al. [10] have suggested that, in order to ensure adequate intensity of a test, individual aerobic capacity should be achieved before conducting an ECT. Conducting a repeated ECT introduces the possibility to adjust the exercise intensity on an individual basis, and the subject tested becomes familiarized with the testing procedure. We hypothesized greater intensities of the repeated ECTs, and consequently a greater number of positive ECT results from the repeated tests. We wanted to bring into focus the challenge of EIB diagnostics. Hence, the purpose of the study was to evaluate the test retest reliability of an exercise challenge test for EIB in a group of referred patients and its association with exercise intensity.

\section{Methods}

\subsection{Study Design}

We conducted a test-retest evaluation study at the Clinic for Allergy and Airway Diseases (KAL) in Oslo. We compared the number of positive ECTs with negative ECTs performed on two different occasions, and assessed a possible association between the test results and exercise intensity. 
Subjects were recruited and tested between August 2010 and March 2011. The subjects visited the clinic three times: on the inclusion day and on the two test days. There were 15 (median) days between the inclusion day and Test Day 1. The subjects completed the repeated ECT between 7 and 28 (mean 14) days after the first ECT. To minimize inter-observer variation, the same test technician performed the measurements on both test days.

Inclusion Day: The routine testing consisted of medical history and anthropometric data registration, skin prick testing for allergy assessment, fractional exhaled nitric oxide $\left(\mathrm{FE}_{\mathrm{NO}}\right)$ measurements, lung function measurements including reversibility to inhalation of short-acting $\beta_{2}$-agonists, static lung volume measurements, residual volume (RV) and total lung capacity (TLC), and pulmonary diffusing capacity for carbon monoxide measurements (DL,CO).

Test Day 1: The procedure included resting blood pressure measurement, resting ECG recording, MVV measurements, an ECT, and treatment with a short-acting $\beta_{2}$-agonist after the ECT.

Test Day 2: The procedure was identical to that on Test Day 1, except for the exclusion of resting blood pressure measurement and resting ECG recording. The exercise intensity (e.g. changed running time, speed, and elevation) of ECT 2 was adjusted by the test technician in collaboration with the test subject, based on ECT 1 .

\subsection{Subjects}

Two pulmonologists recruited 20 patients who had been referred to KAL by their general physicians. Patients of both genders were recruited during consultations following routine testing at the clinic. The inclusion criteria were (1) age between 16 and 45 years, and (2) at least three out of five asthma symptoms associated with physical activity: coughing, wheezing, shortness of breath, lack of physical performance due to respiratory problems, and chest tightness. Subjects who had formerly been diagnosed with and treated for asthma were also included in the study. The exclusion criteria were (1) the lack of ability to perform an ECT with maximum effort, (2) pathological electrocardiography (ECG), and (3) uncontrolled hypertension or any known pulmonary disease other than asthma.

In accordance to ERS guidelines [14], no exercise was undertaken prior to the ECT on the days of testing, inhaled short-acting $\beta_{2}$-agonists were withheld for 8 hours prior to testing, inhaled long-acting $\beta_{2}$-agonists for 72 hours prior to testing, inhaled steroids were withheld on the test days, and antihistamines for 7 days prior to testing.

\subsection{Lung Function}

$\mathrm{FEV}_{1}$ and forced vital capacity (FVC) were measured by maximum expiratory flow volume loops with a spirometer (Flowhandy ZAN 100 USB, nSpire Health GmbH, Oberthulba, Germany) before and 1, 3, 6, 10, and 15 minutes after exercise and 10 minutes after inhalation of Salbutamol $(0.4 \mathrm{mg})$. The measurements were performed according to ERS and ATS guidelines [14]-[19]. We used accepted reference values and took ethnicity into account, i.e. a correction factor was applied to adjust European reference values for application to Africans [16] [20].

\section{Maximum Voluntary Ventilation}

Prior to exercise, MVV was measured for 10 seconds using an analyser (ZAN 600 USB, nSpire Health GmbH, Oberthulba, Germany). The value was multiplied by six, which resulted in the MVV expressed in litres per minute $\left(\mathrm{L} \cdot \mathrm{min}^{-1}\right)$. This was measured to calculate breathing reserve (BR) after measuring $\mathrm{VE}_{\text {peak }}$ during the ECT $\left(\mathrm{MVV}-\mathrm{VE}_{\text {peak }}=\mathrm{BR}\right)$ and to calculate ventilation as a percentage of MVV (VE \% MVV) for the last 4 minutes of the ECT.

\subsection{Exercise Challenge Test}

The ECTs were performed under equal laboratory conditions on both test days, temperature, $20.1^{\circ} \mathrm{C}(0.8)$ [mean $\pm(\mathrm{SD})]$ and $20.2^{\circ} \mathrm{C}(0.8)$ respectively and relative humidity, $28.9 \%$ (7.1) and $28.5 \%$ (7.7) respectively. The test procedure was according to ERS guidelines [14]. Calibration was verified each test day. Exercise was performed by running on a motorized treadmill ( $\mathrm{h} / \mathrm{p} / \operatorname{cosmos}$ quasar med $4.0, \mathrm{~h} / \mathrm{p} /$ cosmos sports $\&$ medical GmbH, Nussdorf-Traunstein, Germany) for 6 - 8 minutes. The initial incline of the treadmill was 3\%. The speed and incline were adjusted throughout the test with the aim of achieving a workload of $\geq 95 \%$ of estimated $\operatorname{HR}_{\max }(220-$ age $)$ 
in the last 4 minutes of each test. Each subject's VE and HR were monitored according to ATS and ERS guidelines, for both ECTs. The ventilation was $>40 \%$ of measured MVV and estimated MVV for each subject, during each of the last 4 minutes of the tests. The HR was $>80 \%$ of estimated $\mathrm{HR}_{\max }$ for each subject during each of the last 4 minutes of the tests. In addition, the subjects assessed their own perception of effort and exhaustion immediately after completing a test, using the Borg CR 10 Scale for rating perceived exertion [21].

$\mathrm{VE}, \mathrm{VO}_{2}$, breathing frequency (BF) and respiratory exchange rate (RER) were measured during exercise. Each subject wore a face mask attached to a flow sensor (ZAN VIP flow sensor, nSpire Health GmbH, Oberthulba, Germany) that was connected to an analyser (ZAN 600 USB, nSpire Health GmbH, Oberthulba, Germany). In order to determine the respiratory flow, gas concentrations were constantly sampled, and by using fast response selective analysers for $\mathrm{O}_{2}$ and $\mathrm{CO}_{2}$ the values were time aligned, providing breath-by-breath measurements. Heart rate was continuously recorded with a heart rate monitor (Polar WearLink W.I.N.D, Polar Electro Oy, Kempele, Finland).

Maximum percentage reduction in $\mathrm{FEV}_{1}$ after exercise test was calculated by (pre-exercise $\mathrm{FEV}_{1}$ - minimum post exercise $\left.\mathrm{FEV}_{1}\right) /\left(\right.$ pre-exercise $\left.\mathrm{FEV}_{1}\right) \times 100 \%$. Minimum post-exercise $\mathrm{FEV}_{1}$ was the lowest recorded value at $1,3,6,10$, or 15 minutes after test, taking the better of two acceptable attempts at each time point. A subject was deemed positive if there was a reduction of $\geq 10 \%$ in $\mathrm{FEV}_{1}$. The highest recorded $\mathrm{VE}, \mathrm{HR}, \mathrm{VO}_{2}, \mathrm{BF}$, and RER values during exercise were determined as $V E_{\text {peak }}, \mathrm{HR}_{\text {peak }}, \mathrm{VO}_{2 \text { peak }}, \mathrm{BF}_{\text {peak }}$ and $\mathrm{RER}_{\text {peak }}$. $\mathrm{VO}_{2}$ and $\mathrm{VE}$ were both measured in $\mathrm{L} \cdot \mathrm{min}^{-1}$, BF in breath $\mathrm{min}^{-1}$, and $\mathrm{HR}$ in beats $\cdot \mathrm{min}^{-1}$. ZAN-Tech Software was used to interpret the results.

\subsection{Fractional Exhaled Nitric Oxide}

$\mathrm{FE}_{\mathrm{NO}}$ was measured using a chemiluminescence analyser (DENOX 88, ECO MEDICS AG, Dürnten, Switzerland). $\mathrm{FE}_{\mathrm{NO}}$ is given in parts per billion (ppb), and we considered $\mathrm{FE}_{\mathrm{NO}}>30 \mathrm{ppb}$ as an indication of airway inflammation.

\subsection{Skin Prick Test}

Skin prick tests were performed with the following allergens: horse dander, dog dander, cat dander, rabbit dander, birch pollen, grass pollen (Timothy (Phleumpratense)), mugwort (Artemisia vulgaris) pollen, fungi Alternariatenuis and (Cladosporium herbarum), house dust mites (Dermatophagoides pteronyssinus), and latex (Soluprick, ALK, Copenhagen, Denmark and Allergopharma, Hamburg, Germany).

\subsection{Static Lung Volumes}

Static lung volumes were measured using bodyplethysmography (ZAN 500 Body USB, nSpire Health GmbH, Oberthulba, Germany). Among the subdivisions of static lung volumes, TLC was recorded and RV calculated.

\subsection{Pulmonary Diffusing Capacity for Carbon Monoxide}

DL, CO was measured using a $\mathrm{CO} / \mathrm{CH}_{4}$ (methane) analyser (ZAN 300 MGA USB, nSpire Health GmbH, Oberthulba, Germany).

\subsection{Statistical Analysis and Ethics}

Subject characteristics are given individually and as mean values and standard deviations. The results are given as means with $95 \%$ confidence intervals. The data were more or less normally distributed, and paired t-tests were applied to assess differences in lung function between baseline and ECT 1 and between baseline and ECT 2. They were also used to assess differences in intensity and maximum reduction in $\mathrm{FEV}_{1}$ between ECT 1 and 2 , $\mathrm{p}<0.05$ was considered statistically significant. Based upon $\mathrm{FEV}_{1}$ as main variable, with pre-existing knowledge of the variation of the variable and assuming a power of $80 \%$, a sample size of 20 subjects was calculated to obtain a significance level of $5 \%$ [22].

All statistical analyses were performed using PASW V.18.0 for Windows software (SPSS Inc, Chicago, Illinois, USA). To create the graph (Figure 1), GraphPadPrism, Version 5.04, GraphPad Software, Inc., California, USA was used. 


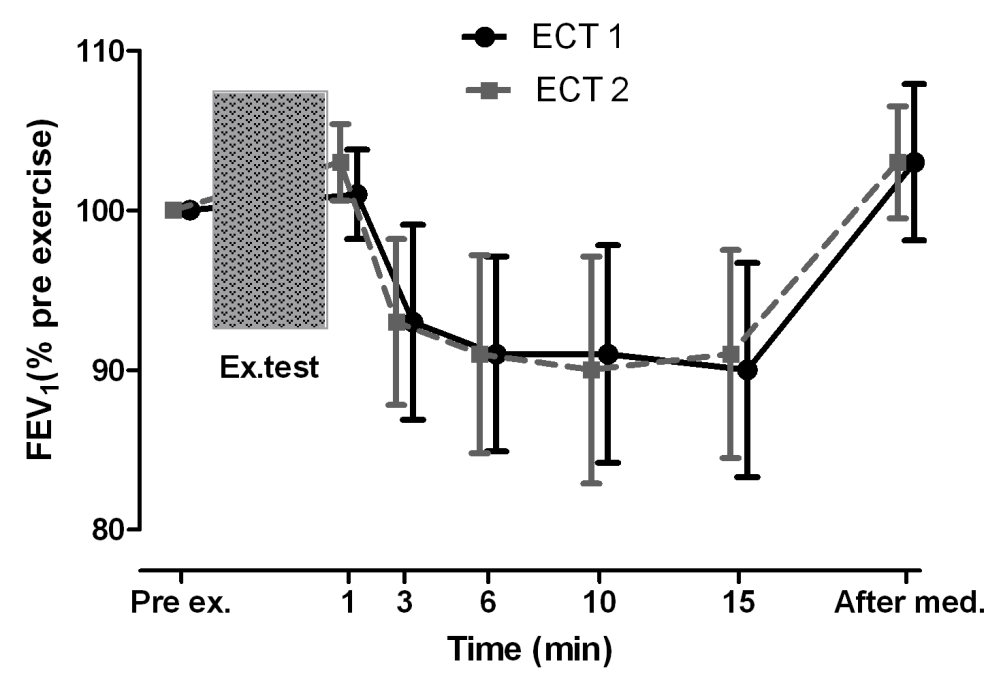

Figure 1. Forced expiratory volume in $1 \mathrm{~s}\left(\mathrm{FEV}_{1}\right)$ pre exercise and 1, 3, 6, 10, and 15 minutes after exercise challenge test (ECT) 1 and 2 and 10 minutes after medication (After med). Results are given as means with $95 \%$ confidence intervals $(n=20)$.

Written informed consent was obtained from each subject. The study was performed in accordance with the principles stated in the Declaration of Helsinki, and was approved by the Regional Committee for Medical Research Ethics, Health Region North, Norway.

\section{Results}

The baseline demographics and disease specific characteristics are shown in Table 1. Blood pressure, ECG, static lung volumes, and diffusing capacities were normal for all subjects. There were no significant differences in the group with regard to lung function $\left(\mathrm{FEV}_{1}\right.$ and $\left.\mathrm{FVC}\right)$ or $\mathrm{FE}_{\mathrm{No}}$ between baseline and test day 1 or between baseline and test day 2.

A total of 7 subjects reported no physical activity at all; one of the subjects smoked and one subject used snuff. However, the subjects did not excel compared with the other subjects regarding asthma symptoms, allergy, and lung function (Table 1).

Five subjects were treated with inhaled steroids (IS). However, three of them had still a severe EIB (Table 1 and Table 3).

On an individual base, exercise intensity measurements were similar for both tests. The subjects' perceptions of their efforts and level of exertion were similar in ECT 1 and ECT 2, and they reported $\geq 9$ on the Borg CR 10 Scale on both tests. Assessment at group level showed no statistical differences in the exercise intensity measurements (Table 2).

Mean VE \% MVV during the last 4 minutes of ECT 1 was 82\%, while for ECT 2 it was $81 \%$. Mean VE \% estimated MVV was $79 \%$ for ECT 1 and $81 \%$ for ECT 2. Mean HR \% predicted $\mathrm{HR}_{\max }$ during the last four minutes was $94 \%$ for ECT 1 and $93 \%$ for ECT 2 . There were no statistical differences in the mean values of $\mathrm{VE}_{\text {peak, }}$ $\mathrm{HR}_{\text {peak }}, \mathrm{VO}_{2 \text { peak }}, \mathrm{BF}_{\text {peak }}$ and $\mathrm{RER}_{\text {peak }}$ or BR between the two ECTs. The mean duration of ECT 1 and ECT 2 differed by 3 seconds.

The agreement in the ECT results was 75\%, with 50\% (10) negative and 25\% (5) positive for both tests (Table 3). Five subjects had a positive test result on only one of the two tests, three on ECT 1, and two on ECT 2.

There was no significant difference in mean maximum reduction in $\mathrm{FEV}_{1}$ (\% pre-exercise) between ECT 1 and ECT 2. The mean maximum reduction in $\mathrm{FEV}_{1}$ was $12 \%$ and $11 \%$ after ECT 1 and ECT 2 respectively. The mean difference was 1 percentage point $(-2.5,4.0),(\mathrm{p}=0.63)$. The mean reduction in $\mathrm{FEV}_{1}$ after $1,3,6,10$, and 15 minutes after exercise and 10 minutes after medication was not significantly different between ECT 1 and ECT 2 (Figure 1). No correlation between baseline $\mathrm{FE}_{\mathrm{NO}}$ and EIB was found in any of the two ECTs, $\mathrm{r}=0.23$ ( $\mathrm{p}$ $=0.46)$ and $r=0.48(p=0.08)$ respectively. This might be due to that only seven subjects had elevated $\mathrm{FE}_{\mathrm{NO}}$ 
Table 1. Baseline characteristics of the subjects $(n=20)$.

\begin{tabular}{|c|c|c|c|c|c|c|c|c|c|c|c|}
\hline \multirow{2}{*}{$\begin{array}{c}\text { No } q, \widehat{\jmath} \\
\mathbf{1}^{1}+\end{array}$} & \multirow{2}{*}{$\begin{array}{c}\text { Age } \\
\text { years }\end{array}$} & \multicolumn{3}{|c|}{$\begin{array}{l}\text { Height, weight, BMI } \\
\quad \mathrm{cm}, \mathrm{kg}, \mathrm{kg} / \mathrm{m}^{2}\end{array}$} & \multirow{2}{*}{$\begin{array}{c}\text { Symptoms } \\
\mathbf{1 , 2 , 3 , 4 , 5} \\
1,2,5\end{array}$} & \multirow{2}{*}{$\begin{array}{c}\text { Atopy } \\
\text { Y, N } \\
Y\end{array}$} & \multirow{2}{*}{$\begin{array}{c}\begin{array}{c}\text { Exercise } \\
\mathbf{h} / \mathbf{w}\end{array} \\
0.5\end{array}$} & \multirow{2}{*}{$\begin{array}{c}\text { FEV }_{\mathbf{1}} \\
\mathbf{L} \\
2.9\end{array}$} & \multirow{2}{*}{$\begin{array}{c}\begin{array}{c}\text { FEV } \\
\text { \% pred. }\end{array} \\
90\end{array}$} & \multirow{2}{*}{$\begin{array}{c}\text { FEV }_{1} / \\
\text { FVC }\end{array}$} & \multirow{2}{*}{ 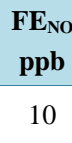 } \\
\hline & & 163 & 73 & 27 & & & & & & & \\
\hline $2^{\mathrm{a}, 1,3}+$ & 27 & 163 & 48 & 18 & $1,2,5$ & $\mathrm{~N}$ & 0.0 & 3.4 & 109 & 89 & 6 \\
\hline $3^{1,2}+$ & 22 & 163 & 61 & 23 & $1,2,3,5$ & $\mathrm{~N}$ & 4.5 & 3.0 & 92 & 68 & 61 \\
\hline $4^{1,3}+$ & 39 & 171 & 66 & 23 & $3,4,5$ & $\mathrm{~N}$ & 0.5 & 2.8 & 88 & 68 & 13 \\
\hline 5 & 36 & 188 & 71 & 20 & $1,2,3,4,5$ & $\mathrm{Y}$ & 2.0 & 4.6 & 101 & 72 & 28 \\
\hline $6^{1,3}+$ & 35 & 183 & 95 & 28 & $1,2,4,5$ & $\mathrm{~N}$ & 1.0 & 4.1 & 108 & 80 & 7 \\
\hline $7 \hat{\jmath}$ & 27 & 179 & 73 & 23 & $1,2,3$ & $\mathrm{~N}$ & 5.0 & 3.7 & 84 & 72 & 73 \\
\hline $\mathbf{8}+$ & 21 & 160 & 63 & 25 & $1,3,5$ & $\mathrm{~N}$ & 1.5 & 3.4 & 108 & 89 & 46 \\
\hline $\mathbf{9} q$ & 20 & 166 & 62 & 23 & $1,3,5$ & $\mathrm{~N}$ & 2.0 & 3.0 & 90 & 86 & 22 \\
\hline $\mathbf{1 0}^{1}+$ & 18 & 156 & 53 & 22 & $1,2,3,4,5$ & $\mathrm{Y}$ & .0 & 2.5 & 85 & 86 & 60 \\
\hline $11^{1} \partial^{\lambda}$ & 23 & 189 & 89 & 25 & $1,2,3$ & $\mathrm{Y}$ & 4.0 & 5.0 & 100 & 79 & 69 \\
\hline $12+$ & 29 & 165 & 63 & 23 & $1,2,3,5$ & $\mathrm{Y}$ & 1.0 & 3.3 & 103 & 82 & 65 \\
\hline $13^{1,3}+$ & 28 & 163 & 69 & 26 & $1,2,5$ & $\mathrm{~N}$ & 0.0 & 3.1 & 97 & 79 & $m$ \\
\hline $\mathbf{1 4}+$ & 24 & 167 & 69 & 25 & $1,2,3,5$ & $\mathrm{Y}$ & 0.0 & 3.5 & 104 & 88 & $m$ \\
\hline $15^{\mathrm{b}} \hat{\mathrm{O}}$ & 31 & 181 & 75 & 23 & $1,2,3,5$ & $\mathrm{~N}$ & 0.0 & 4.8 & 109 & 70 & 5 \\
\hline $16{ }^{\lambda}$ & 29 & 194 & 84 & 22 & $1,3,4,5$ & $\mathrm{Y}$ & 7.0 & 5.1 & 103 & 73 & 12 \\
\hline $17 \widehat{\partial}$ & 31 & 175 & 67 & 22 & $1,3,5$ & $\mathrm{Y}$ & 0.0 & 3.7 & 90 & 82 & 15 \\
\hline $\mathbf{1 8}^{1}+$ & 27 & 168 & 72 & 26 & $1,2,3,5$ & $\mathrm{Y}$ & 1.0 & 2.9 & 86 & 76 & 15 \\
\hline $19{ }^{\lambda}$ & 35 & 176 & 71 & 23 & $1,2,3,5$ & $\mathrm{Y}$ & 2.0 & 4.2 & 103 & 81 & 14 \\
\hline $20^{\mathrm{c}, \mathrm{d}, 1,3} \widehat{\partial}$ & 26 & 164 & 65 & 24 & $2,3,5$ & $\mathrm{Y}$ & 0.0 & 1.6 & 46 & 67 & 55 \\
\hline $\begin{array}{l}\text { Mean } \\
\text { (SD) }\end{array}$ & $\begin{array}{l}28 \\
(6)\end{array}$ & $\begin{array}{c}172 \\
(11)\end{array}$ & $\begin{array}{c}69 \\
(11)\end{array}$ & $\begin{array}{c}24 \\
(2)\end{array}$ & & & $\begin{array}{c}1.6 \\
(2.0)\end{array}$ & $\begin{array}{c}3.5 \\
(0.9)\end{array}$ & $\begin{array}{c}95 \\
(14)\end{array}$ & $\begin{array}{l}79 \\
(7)\end{array}$ & $\begin{array}{c}32 \\
(25)\end{array}$ \\
\hline Sum $12 / 8$ & & & & & $18 / 15 / 16 / 5 / 18$ & $11 / 9$ & & & & & \\
\hline
\end{tabular}

Notes: Body mass index (BMI); symptoms (1: cough, 2: wheeze, 3: shortness of breath, 4: lack of physical performance due to respiratory problems, and 5: chest tightness); yes $(\mathrm{Y})$; no $(\mathrm{N})$; exercise (h/w, hours of endurance training per average week); forced expiratory volume in $1 \mathrm{~s}\left(\mathrm{FEV} \mathrm{V}_{1}\right.$ in litres and in percentage of predicted); forced vital capacity (FVC); fractional exhaled nitric oxide (FE $\mathrm{F}_{\mathrm{NO}}$ in ppb parts per billion); ${ }^{\mathrm{a}}$ smoker, ${ }^{\mathrm{b}}$ snuff user, ${ }^{\mathrm{c}} \mathrm{African}$, positive reversibility test, ${ }^{1,2,3}$ medication (1: short-acting $\beta_{2}$-agonists, 2 : long-acting $\beta_{2}$-agonists, 3 : inhaled steroids); and $m$ missing value.

values above $30 \mathrm{ppb}$ (Table 1) and show that subjects with different asthma phenotypes are included in the present study.

\section{Discussion}

The divergence in the ECT results was not associated with the exercise intensity.

Contra to our hypothesis, the subjects evidently achieved maximal performance in the first ECT (Table 2). According to Carlsen et al. [11], mean heart rate measured as a percentage of estimated $\mathrm{HR}_{\max }$ in the last 4 minutes of ECTs represents an adequate intensity level. The subjects' perception of their exertion on both tests also indicates maximal exertion. Consequently, the adjustments to the repeated ECTs did not result in any significantenhancements to intensity.

The five subjects with different test results had only mild reductions in $\mathrm{FEV}_{1}$, as shown in a study by Anderson et al. [12], suggesting that for subjects with mild symptoms more than one test may be required.

The included subjects were to some extent physically active in their leisure time, but only three subjects 
Table 2. Intensity of exercise challenge test 1 and 2 for the subjects $(n=20)$.

\begin{tabular}{|c|c|c|c|c|}
\hline Variable & ECT 1 Mean (SD) & ECT 2 Mean (SD) & Difference Mean (95\% CI) & $\boldsymbol{P}$ \\
\hline VE \% MVV & $82(16)$ & $81(18)$ & $-2.7(-7.4,2.1)$ & 0.25 \\
\hline VE \% estimated MVV & $79(8)$ & $81(12)$ & $-1.6(-4.7,1.5)$ & 0.30 \\
\hline HR \% estimated $H R_{\max }$ & $94(4)$ & $93(4)$ & $-0.0(-1.4,1.3)$ & 0.94 \\
\hline$V E_{\text {peak }}\left(L \cdot \min ^{-1}\right)$ & $112(27)$ & $118(32)$ & $-0.5(-3.8,2.7)$ & 0.74 \\
\hline $\mathrm{HR}_{\text {peak }}\left(\right.$ beats·min ${ }^{-1}$ ) & $186(8)$ & $184(9)$ & $-0.2(-1.8,1.5)$ & 0.81 \\
\hline $\mathrm{VO}_{2 \text { peak }}\left(\mathrm{ml} \cdot \mathrm{kg}^{-1} \cdot \mathrm{min}^{-1}\right)$ & $44(6)$ & $46(8)$ & $0.6(-0.7,1.9)$ & 0.36 \\
\hline BF $_{\text {peak }}$ (breath min $^{-1}$ ) & $56(8)$ & $56(9)$ & $-0.5(-2.9,1.9)$ & 0.65 \\
\hline RER $_{\text {peak }}$ & $1.11(0.05)$ & $1.10(0.05)$ & $-0.013(-0.033,0.018)$ & 0.21 \\
\hline $\operatorname{BR}\left(L \cdot \min ^{-1}\right)$ & $8(22)$ & $15(19)$ & $8.9(-2.4,20.3)$ & 0.12 \\
\hline
\end{tabular}

Ventilation (VE) \% of maximal voluntary ventilation (MVV); VE \% of estimated MVV and heart rate (HR) \% of estimated HR maximum (HR max $_{\text {in }}$ the last 4 minutes (mean) of exercise challenge test (ECT) 1 and 2; Peak ventilation $\left(\mathrm{VE}_{\text {peak }}\right)$, peak heart rate $\left(\mathrm{HR}_{\text {peak }}\right)$, peak oxygen uptake $\left(\mathrm{VO}_{2 \text { peak }}\right)$, peak breathing frequency $\left(\mathrm{BF}_{\text {peak }}\right)$, peak respiratory exchange ratio $\left(\mathrm{RER}_{\text {peak }}\right)$ and breathing reserve $(\mathrm{BR})$ of the ECTs. Difference: negative values relate to greater intensity of ECT 1 . Mean ECT 2 -mean ECT $1 \neq$ mean difference due to missing values.

Table 3. Maximum reduction in forced expiratory volume in $1 \mathrm{~s}\left(\mathrm{FEV}_{1}\right)$ from before to after exercise challenge test (ECT) 1 and 2, and the test results (positive/negative).

\begin{tabular}{|c|c|c|}
\hline Subject No & ECT 1 Reduction \% (Result) & ECT 2 Reduction \% (Result) \\
\hline 3 & -65 (pos) & -58 (pos) \\
\hline 6 & -13 (pos) & -33 (pos) \\
\hline 8 & -15 (pos) & -10 (pos) \\
\hline 11 & -18 (pos) & -20 (pos) \\
\hline 20 & -34 (pos) & -33 (pos) \\
\hline 2 & -4 (neg) & -2 (neg) \\
\hline 4 & -2 (neg) & -3 (neg) \\
\hline 5 & -3 (neg) & -4 (neg) \\
\hline 9 & -3 (neg) & -6 (neg) \\
\hline 13 & -2 (neg) & -2 (neg) \\
\hline 14 & -5 (neg) & -3 (neg) \\
\hline 15 & -9 (neg) & 1 (neg) \\
\hline 16 & -4 (neg) & 0 (neg) \\
\hline 17 & 1 (neg) & -4 (neg) \\
\hline 19 & -6 (neg) & -8 (neg) \\
\hline 1 & -14 (pos) & -8 (neg) \\
\hline 7 & -16 (pos) & -2 (neg) \\
\hline 10 & -13 (pos) & -9 (neg) \\
\hline 12 & -8 (neg) & -10 (pos) \\
\hline 18 & -9 (neg) & -13 (pos) \\
\hline
\end{tabular}


participated in competitive sports. The subjects' activity levels differed, and the difference was reflected in their $\mathrm{VO}_{2 \text { peak }}$ results (range 32 - 61, mean 45) $\mathrm{ml} \mathrm{kg}^{-1} \cdot \mathrm{min}^{-1}$. Three subjects had some previous experience of ECTs, in contrast to three subjects who had not run on a treadmill before. The difference in their experience was not reflected in the subjects' ECT performances.

Respiratory muscle fatigue should not be disregarded [23], and since the last lung function measurement was 15 minutes after the ECT, occasional late responses may have been overlooked [2]. Two of the patients had a reduction in $\mathrm{FEV}_{1}$ of $8 \%$ and $9 \%$ respectively 15 minutes after ECT1and both had a reduction in $\mathrm{FEV}_{1}>10 \%$ after ECT2. It may be speculated whether a further reduction in $\mathrm{FEV}_{1}$ would have occurred if measurements had been continued for 20 and 30 minutes after ECT1. However, the lowest FEV ${ }_{1}$ value measured in the other patients in the study was 6 and 10 minutes after ECT1 and ECT2, and therefore late responses are unlikely. It cannot be ruled out that the use of inhaled steroids decreased the likelihood of a positive test result [6], and we cannot exclude the possibility that the test results may have been influenced by either variations in outdoor weather conditions or that the subjects were tested within or not within the season that they suffered from an allergy. However, the ambient condition during the two exercise tests was standardized with the same relative humidity and temperature, the baseline lung function and $\mathrm{FE}_{\mathrm{NO}}$ did not differ between the tests, and since the subjects were their own controls and both tests were performed within a period of approximately 14 days, the weather and seasonal variations in allergic responses were controlled for as far as possible.

Standardization of the testing procedures was secured by using the same technician. Performing an ECT is mentally and physically demanding, yet there were no dropouts. The study was conducted at a centre of expertise, and reflected the challenges faced in an everyday clinical setting. The study was not repeated as a blind study, and psychological factors that might have influenced the technician and the tested subjects cannot be excluded. Due to a relatively small sample size, the results should be interpreted with caution and the findings should not be generalized.

We have shed light on the challenges of EIB diagnostics. Our results may suggest that a repeated ECT does not improve ECT performance with regard to exercise intensity. Still, it should be underlined that repeated testing could be of value to patients with mild symptoms. In patients with season-dependent symptoms, or in situations where a technician suspects lack of optimal exercise performance despite ATS/ERS criteria fulfilment, a second test could be useful. Knowledge about the usefulness of a repeated ECT is of importance to patients, clinical practice, and research work. A reliable assessment of EIB is of great value, as it can enable optimal choices of treatment and adaptations relating to exercise and sports.

\section{Conclusion}

In summary our study showed a $25 \%$ divergence in the results of two consecutive ECTs in the case of subjects with symptoms strongly indicative of EIB. The difference in test results was not explained by a difference in exercise intensity, thus suggesting that better diagnostic procedures should be developed.

\section{Acknowledgements}

The authors would like to thank all the patients who participated in the study. We thank Lene Grønnerød Sundby, General Manager at the clinic, and all other staff that facilitated the data collection and contributed to the positive spirit at the clinic. We also thank Petter Mowinckel for thorough statistical advice and assistance.

\section{References}

[1] Nedocromil Sodium for Preventing Exercise-Induced Bronchoconstriction. Cochrane Database of Systematic Reviews [Database on the Internet] 2002.

[2] Mast-Cell Stabilising Agents to Prevent Exercise-Induced Bronchoconstriction. Cochrane Database of Systematic Reviews [Database on the Internet] 2003.

[3] Ernst, P., Ghezzo, H. and Becklake, M.R. (2002) Risk Factors for Bronchial Hyperresponsiveness in Late Childhood and Early Adolescence. European Respiratory Journal, 20, 635-639. http://dx.doi.org/10.1183/09031936.02.00962002

[4] Rupp, N.T. (1996) Diagnosis and Management of Exercise-Induced Asthma. The Physical and Sports Medicine, 24, 77-87. http://dx.doi.org/10.3810/psm.1996.01.1213

[5] Rundell, K.W., Im, J., Mayers, L.B., et al. (2001) Self-Reported Symptoms and Exercise Induced Asthma in the Elite 
Athlete. Medicine \& Science in Sports \& Exercise, 33, 208-213. http://dx.doi.org/10.1097/00005768-200102000-00006

[6] Crapo, R.O., Casaburi, R., Coates, A.L., et al. (2000) Guidelines for Methacholine and Exercise Challenge Testing1999. American Journal of Respiratory and Critical Care Medicine, 161, 309-329. http://dx.doi.org/10.1164/ajrccm.161.1.ats11-99

[7] Sterk, P.J., Fabbri, L.M., Quanjer, P.H., et al. (1993) Airway Responsiveness. Standardized Challenge Testing with Pharmacological, Physical and Sensitizing Stimuli in Adults. European Respiratory Journal, 6, 53-83. http://dx.doi.org/10.1183/09041950.053s1693

[8] Weiler, J.M., Bonini, S., Coifman, R., et al. (2007) American Academy of Allergy, Asthma \& Immunology Work Group Report: Exercise-Induced Asthma. The Journal of Allergy and Clinical Immunology, 119, 1349-1358. http://dx.doi.org/10.1016/j.jaci.2007.02.041

[9] Tanaka, H., Monahan, K.D. and Seals, D.R. (2001) Age-Predicted Maximal Heart Rate Revisited. Journal of the American College of Cardiology, 37, 153-156. http://dx.doi.org/10.1016/S0735-1097(00)01054-8

[10] Trümper, C., Mäueler, S., Vobejda, C., et al. (2009) Heart Rate-Based Protocols for Exercise Challenge Testing Do Not Ensure Sufficient Exercise Intensity for Inducing Exercise-Induced Bronchial Obstruction. British Journal of Sports Medicine, 43, 429-431. http://dx.doi.org/10.1136/bjsm.2007.041715

[11] Carlsen, K.H., Engh, G. and Mørk, M. (2000) Exercise-Induced Bronchoconstriction Depends on Exercise Load. Respiratory Medicine, 94, 750-755. http://dx.doi.org/10.1053/rmed.2000.0809

[12] Anderson, S.D., Pearlman, D.S., Rundell, K.W., et al. (2010) Reproducibility of the Airway Response to an Exercise Protocol Standardized for Intensity, Duration, and Inspired Air Conditions, in Subjects with Symptoms Suggestive of Asthma. Respiratory Research, 11, 120-132. http://dx.doi.org/10.1186/1465-9921-11-120

[13] Carlsen, K.H., Anderson, S.D., Bjermer, L., et al. (2008) Exercise-Induced Asthma, Respiratory and Allergic Disorders in Elite Athletes: Epidemiology, Mechanisms and Diagnosis: Part 1 of the Report from the Joint Task Force of the European Respiratory Society (ERS) and the European Academy of Allergy and Clinical Immunology (EAACI) in cooperation with GA2LEN. Allergy, 63, 387-403. http://dx.doi.org/10.1111/j.1398-9995.2008.01662.x

[14] Roca, J., Whipp, B.J., Agusti, A.G.N., et al. (1997) Clinical Exercise Testing with Reference to Lung Diseases: Indications, Standardization and Interpretation Strategies. European Respiratory Journal, 10, 2662-2689. http://dx.doi.org/10.1183/09031936.97.10112662

[15] ATS, ERS (2005) ATS/ERS Recommandations for Standardized Procedures for the Online and Offline Measurement of Exhaled Lower Respiratory Nitric Oxide and Nasal Nitric Oxide. American Journal of Respiratory and Critical Care Medicine, 171, 912-930. http://dx.doi.org/10.1164/rccm.200406-710ST

[16] Cotes, J.E., Chinn, D.J., Quanjer, P.H., et al. (1993) Standardization of the Measurement of Transfer Factor (Diffusing Capacity). European Respiratory Journal, 6, 41-52. http://dx.doi.org/10.1183/09041950.041s1693

[17] Dreborg, S. (2005) Evaluation of Allergen Exposure. The Journal of Allergy and Clinical Immunology, 116, 620-622. http://dx.doi.org/10.1016/j.jaci.2005.06.027

[18] Miller, M.R., Hankinson, J., Brusasco, V., et al. (2005) Standardization of Spirometry. European Respiratory Journal, 26, 319-338. http://dx.doi.org/10.1183/09031936.05.00034805

[19] Wanger, J., Clausen, J.L., Coates, A., et al. (2005) Standardization of the Measurement of Lung Volumes. European Respiratory Journal, 26, 511-522. http://dx.doi.org/10.1183/09031936.05.00035005

[20] Quanjer, P.H., Tammeling, G.J., Cotes, J.E., et al. (1993) Lung Volumes and Forced Ventilatory Flows. European Respiratory Journal, 6, 5-40. http://dx.doi.org/10.1183/09041950.005s1693

[21] Borg, G. (1998) Borg’s Perceived Exertion and Pain Scales. Human Kinetics, Champaign.

[22] Hofstra, W.B., Sont, J.K., Sterk, P.J., et al. (1997) Sample Size Estimation in Studies Monitoring Exercise-Induced Bronchoconstriction in Asthmatic Children. Thorax, 52, 739-741. http://dx.doi.org/10.1136/thx.52.8.739

[23] Rundell, K.W. and Sue-Chu, M. (2010) Field and Laboratory Exercise Challenges for Identifying Exercise-Induced Bronchoconstriction. Breathe, 7, 35-42. http://dx.doi.org/10.1183/18106838.0701.034 